\title{
Pele branca, máscaras negras em $O$ esplendor de Portugal de António Lobo Antunes
}

\author{
Agnès Levécot \\ Sorbonne Nouvelle - Crepal
}

\begin{abstract}
Resumo
As máscaras trazidas da África que acompanham o percurso de Carlos, retornado de Angola, não escondem mas, pelo contrário, revelam: depois de terem perdido, nas mãos dos colonos, o seu poder simbólico tradicional, apenas servem para acusar a origem mestiça da personagem principal e ganham, sob a pena de António Lobo Antunes, a força de um símbolo ideológico que denuncia o fracasso da "grandeza" colonial enfaticamente proclamada pelo regime salazarista.
\end{abstract}

Palavras-chaves: máscara; racismo; colonial; identidade.

\section{Résumé}

Les masques rapportés d'Afrique qui accompagnent le parcours de Carlos, rapatrié de l'Angola, ne cachent pas mais au contraire révèlent : après avoir perdu, aux mains des colons, leur force symbolique traditionnelle, ils ne servent plus qu'à accuser l'origine métisse du personnage principal, et ils gagnent, sous la plume de l'écrivain, la force d'un symbole idéologique qui dénonce la faillite de la «grandeur» coloniale emphatiquement proclamée par le régime salazariste.

Mots-clés: masque; racisme; colonial; identité.

Recebido em: 19/11/2019

Aprovado em: 07/08/2020

Carlos espera pelos seus irmãos, Rui e Clarisse, para a ceia de Natal, tempo de espera que se converte, pela pena de António Lobo Antunes, em tempo de recordação individual e coletiva restituindo a história duma família de colonos portugueses e, através dela, a história de dois países, Angola e Portugal, entre 1978 e 1995. Após a morte do pai, a mãe Isilda envia seus filhos para a metrópole a fim de protegê-los da guerra civil que vai alastrando em terras angolanas após a independência. Lena, mulher de Carlos, trouxe das terras africanas cinco máscaras tradicionais que ela colocou, logo à chegada a Lisboa, nas paredes da sala do apartamento onde recolheram os irmãos:

[...] a Lena [que], mal entrámos, mesmo antes de começar a limpar a fuligem, as traças e as vespas da casa, as retitrou do seu pedaço de jornal em precauções de tesouro livrando-se dos protestos da Clarisse com as costas da mão 
— Se penduras essa porcaria no apartamento não estás boa da cabeça Lena de forma que dei conta - O que se passa Lena? (ANTUNES, 1999, p. 123).

No seu percurso transcontinental, as esculturas perdem a sua função original virando objetos-recordação de um passado afetivo para Lena, objetos atormentadores para Carlos, objetos símbolos para o autor, e objetos "disertos" para o leitor: a sua presença iterativa e insistente na vida das personagens e ao longo do texto lembra constantemente a origem mestiça de Carlos indiciando simultaneamente a errância identitária dos irmãos e de toda a nação portuguesa na sequência do 25 de Abril de 1974, ao mesmo tempo que denuncia a falência da "grandeza" do império colonial enfaticamente proclamada pelo antigo regime português.

O percurso destas máscaras caracteriza-se por uma oscilação entre movimento e fixidez correspondendo à oposição vida/morte, material/espiritual das tradições africanas relacionadas com o uso de tais objetos. No entanto, o movimento de vaivém intercontinental da família vêse aniquilado pelo regresso definitivo à metrópole dos descendentes da família de colonos que, ao mesmo tempo que tenta assegurar a sua sobrevivência material, arrasta a sua decadência psicológica e social.

As circunstâncias da compra das máscaras e as condições em que foram literalmente arrancadas da sua terra de origem para serem penduradas nas paredes de um medíocre apartamento lisboeta remetem metaforicamente, num primeiro momento, para o desconhecimento das culturas africanas e a falta de interesse por elas, assim como a falta de empatia dos colonos portugueses para com as populações autóctones: no discurso das personagens, os angolanos são animalizados, tratados como inferiores, e, posteriormente, as máscaras compradas à socapa em Luanda aparecem no texto apenas como uma mera sombra material dum povo desprezado:

as caras de madeira que trouxemos de Angola, cinco caras compradas por tuta e meia aos vendedores da marginal impingindo-as de mesa em mesa nas esplanadas, atravessavam a avenida para se aninharem sob as palmeiras trocando insultos e cigarros, gritando-nos num piarzito agudo

— Patrão, patrão (ANTUNES, 1999, p. 122).

$\mathrm{Na}$ vida deprimente dos irmãos retornados, elas apenas materializam mentalidades e ressentimentos. Para Clarisse, que não responde ao convite do irmão e o imagina à sua espera, elas são "horríveis" (ANTUNES, 1999, p. 379). A primeira manifestação de hostilidade para com estas figuras de madeira vem da mãe Isilda quando, temendo pela vida dos seus filhos, condu-los até o cais de embarque de Luanda para os meter no próximo navio de retorno à metrópole. O episódio é relatado em modo tragicômico: comprometendo a vida de toda a família numa altura em que se tratava de escapar aos perigos duma cidade devastada pela guerra civil, ela trava perigosamente o jipe ao aperceber-se da presença das máscaras dentro da viatura. 
— Quem meteu esta bodega no meu carro?

Canhões, metralhadoras, gases desfolhantes, napalm levantando chamas de fósforo, a gente a descoberto no alcatrão a imaginar

— Vamos morrer aqui (ANTUNES, 1999, p. 122).

A insistência de Lena em levar as máscaras para Lisboa, na realidade, pouco tem a ver com o seu valor estético. Num primeiro momento, trata-se de uma necessidade que ela parece ter de salvaguardar uma recordação de um momento fundador da vida africana duma família de pequenos colonos portugueses: a construção da casa familiar cujo caráter ao mesmo tempo modesto e afetivo, aqui reforçado pelo uso de sufixos diminutivos, denuncia as condições de vida por vezes rudimentares dos pequenos colonos ao chegarem às terras africanas em que tinham de construir tudo de raiz e com poucos meios materiais:

que as máscaras eram o mesmo que a vivendinha do pai junto ao musseque, construída durante os fins-de-semana com os sobejos de tijolo, areia e cimento de uma obra interrompida, um murozito de arabescos de gesso, um portão de metal barato com lanças pintadas de laranja no bico (ANTUNES, 1999, p. 123).

Entretanto, a permanência destas máscaras no seio da família passa a ter um significado muito mais complexo e profundo. Tradicionalmente carregadas de significados plurais e profundos, religiosos e filosóficos, são aqui qualificadas de "carantonhas" (ANTUNES, 1999, p. 199). Objetos criativos, portadores de símbolos e representantes duma cultura, animados pelas crenças dos seus utentes, esvaziam-se dos seus significados passando a exercer uma função contrária àquela para que foram destinados originalmente: idealizados e concebidos para afastarem os maus espíritos, passam a alimentar um discurso com dimensão demoníaca catalisando forças perigosas e ameaçadoras. Penduradas na parede lisboeta, das "carantonhas" emerge pouco a pouco a imagem ao mesmo tempo de uma negritude rejeitada e da incomunicabilidade que vai aumentando e destruindo a vida da família ao longo do tempo. Os seus olhos ocos e a sua boca muda perseguem as personagens realçando a sua incapacidade comunicativa e o peso do não dito reificados nas cartas que a mãe envia aos filhos, sistematicamente guardadas dentro de uma gaveta sem sequer serem abertas.

Esse silêncio paira por cima da pessoa de Carlos, que carrega na pele a marca do seu nascimento: ele é fruto de uma relação ilegítima do pai com uma empregada africana da empresa Cotonang, onde trabalhava. Na sua terra natal, o meio-irmão de Clarisse e Rui percebeu muito cedo a rejeição de que é vítima: logo na infância, notou que as pessoas fingiam não ver a sua diferença (ANTUNES, 1999, p. 76), mas não lhe falavam como às outras crianças (ANTUNES, 1999, p. 95): tratavam-no por "rapaz" e não pelo nome como aos irmãos (ANTUNES, 1999, p. 101). Ele então perguntava às empregadas por que o alcunhavam de "preto" na escola (ANTUNES, 1999, p. 98), por que lhe davam um tratamento diferente, e confiava-lhes as suas 
dúvidas e angústias. Imaginava que "o capataz ia chegar à cozinha e mandá-lo [mandar-me] trabalhar na safra, tiravam-lhe [me] o quarto, os brinquedos, o seu [meu] lugar à mesa, comia funje e peixe seco" (ANTUNES, 1999, p. 97). Cedo então percebeu por que não o deixavam comer à mesa com as visitas: "um dia percebi que não era por não haver lugar à mesa nem pela Clarisse, nem pelo Rui, era por medo que os estrangeiros reparassem que não era branco, era preto como os contratados" (ANTUNES, 1999, p. 124). Logo em criança Carlos começou a questionar a hierarquia racial estabelecida quando constatou que, no presépio de Natal, os reis magos eram posicionados desigualmente: “[...] reis magos brancos à frente do rei mago preto, não o rei mago preto à frente dos reis magos brancos, os reis magos brancos mandavam nos brancos e o rei preto nos pretos" (ANTUNES, 1999, p. 343). Já casado e ainda em Angola, ele compreendeu que a Lena não queria engravidar dele "por não trazer a vergonha de um mestiço na barriga, a empestar-lhe o berço, a empestar-lhe a casa, entendi porque fugia na cama mal começava a expandir-me no cobertor" (ANTUNES, 1999, p. 95).

Em Lisboa, as máscaras inicialmente rejeitadas pela mãe são agora desprezadas por Clarisse, mas evidenciadas por Lena, que através delas exprime o seu desprezo pelo seu marido: ciente do perigo duma provável segregação por parte da sociedade lisboeta, ela rejeita-o lamentando "não ter casado com um vizinho qualquer da sua raça" (ANTUNES, 1999, p. 101). Nesse contexto, a exposição das esculturas de madeira tem como finalidade uma forma de assédio psicológico a Carlos, lembrando-lhe incessantemente a transgressão social de que ele é o fruto. Máscaras de um carnaval trágico, elas exprimem "as pantomimas com que o bárbaro canta a sua vitória sobre as forças caóticas do mal" (MAERTENS, 1978, p. 90). ${ }^{1} \mathrm{E}$ isto porque, acrescenta o teórico, "a uma sociedade que, para assegurar a sua sobrevivência, só conhece a regra e a sanção de excomunicação do elemento perturbador, a máscara ensina o não-dito da regra" (MAERTENS, 1978, p. 19). Outro estudioso explica que o uso da máscara tem a ver com a perturbação da ordem habitual das coisas, "quer por inspiração divina, quer porque a sua instituição decorre diretamente de uma violação do interdito" (BÉDOUIN, 1961, p. 23). É precisamente o que se passa com os povos da região donde provêm as máscaras, a Lunda (ANTUNES, 1999, p. 128 e 199), onde elas são usadas para ironicamente revelar as suas próprias culpas (REDINHA, 1965, p. 13). No contexto desta família, aquelas peças constituem portanto um espelho que remete constantemente para a transgressão do pai e para a sua condenação pela sociedade racista cujo discurso é perpetuado pela avó de Carlos, mãe de Isilda, que teme o nascimento de novo mestiço na família:

[...] um segundo mestiço na família nunca, mesmo o Carlos que ninguém julgava mestiço, não parecia mestiço, a minha avó encolhia-se toda se ele a beijava, cheiravase enojada por cheirar a senzala, tirava a água-de-colónia da algibeira, não lhe oferecia

A tradução dos textos teóricos escritos em francês é da nossa responsabilidade. 
prenda de Natal como à minha irmã e a mim, evitava-o, fingia não o ouvir se falava com ela, a minha avó para quem os africanos eram não uma raça diferente mas uma espécie zoológica distinta capazes até certo ponto de imitar as pessoas e todavia sem nada meu Deus que os aparentasse a nós, basta ver do que se alimentam que até baratas engolem, basta ver como andam, reparar como transportam os filhotes, iguaizinhos aos mandris [...] (ANTUNES 1999, p. 151).

O discurso da avó é logicamente reproduzido pelos irmãos de Carlos: “digam-me se há coisa mais triste do que encontrar consolo na companhia de uma africana, conversar com uma africana...”, declara o Rui (ANTUNES, 1999, p. 244).

Por isso, Carlos sabe perfeitamente que "a Lena trouxe as máscaras para lhe [me] fazer ver que não nasc[i]eu na propriedade com os [meus] seus irmãos” (ANTUNES, 1999, p. 125), para lhe lembrar incessantemente a sua origem, que ele não nasceu na fazenda como os seus irmãos, e que não pode ter o mesmo estatuto que o resto do agregado colonial (ANTUNES, 1999, p. 125-126). A máscara, de fato, mostra, evidencia muito mais do que dissimula, e foi por isso, pensa Carlos, que a primeira ação de Lena foi pendurar as máscaras na parede principal da sala (ANTUNES, 1999, p. 123), ela assim afirmando o seu poder ao mesmo tempo que o mortificava a ele. Qual Atena colocando no centro do seu escudo a cabeça da Medusa, que transformava em pedra os que ousavam olhar para ela, Lena bota no centro do espaço familiar o reflexo daquele que ela considera como impuro. Esse ato constitui uma tomada de poder que reduz a existência do seu marido a uma imagem negativa: "Basta que se consiga fixar o Outro, médusé (estupefato), no 'estágio do espelho', onde reina o princípio da identidade, o corte entre sujeito e objeto, para reduzi-lo a nada" (MAERTENS, 1978, p. 91).

A onipresença e a perseguição dos olhares ocos das peças africanas projetam portanto a sombra da ruptura familiar, e reforçam na personagem de Carlos a dicotomia sujeito/objeto que o levou, desde a infância, a um questionamento identitário recorrente e desestabilizador:

Carlos

e eu era diferente daquele nome, não era aquele nome, não podia ser aquele nome, as pessoas quando chamavam

Carlos

chamavam um Carlos que era eu em elas não eu nem era eu em eu, era um outro, da mesma forma que se lhes respondia não era eu quem respondia era o eu deles que falava e o eu em eu calava-se em mim e eu permanecia um estranho, um estrangeiro, um eu que era dois, o deles e o meu, e o meu por ser apenas meu não era e então dizia como eles diziam

Carlos (ANTUNES, 1999, p. 127).

Carlos não é nem negro nem branco e não se consegue integrar numa sociedade regida por uma hierarquia racial. As máscaras representam ao mesmo tempo a rejeição do Outro para 
com ele próprio e do Outro da sua família. "A máscara brota do vazio que separa o sujeito do objeto, o outro do Outro" e, acrescenta J.-T. Maertens, "ganha ao sair do vazio dois rostos diferentes, um tanto como o outro estagnados na morte" (MAERTENS, 1978, p. 85). Símbolos de vida e materialização do espiritual quando usados em rituais que marcam as grandes etapas da vida (REDINHA, 1965, p. 13), as máscaras simbolizam aqui a morte social e identitária das personagens ao mesmo tempo que do império português e da sociedade idealizada pelos seus mentores. A representação mimética desses objetos testemunha certo modo de relação com o mundo e reifica uma ideologia subjacente. O símbolo sendo mediador entre o mundo físico e o mundo do pensamento, o implícito destas figuras engloba os modos de pensamentos da sociedade portuguesa da época. Podemos portanto considerar que a personagem de Carlos, através da imagem denunciadora e destrutora destas máscaras, representa metonímica e simbolicamente o fracasso do sonho transcontinental português: a "paz plurirracial" e a miscigenação cultural da "lusitanidade", da teoria lusotropicalista recuperada e reiteradamente pregada pelo antigo regime, falharam redondamente. A mestiçagem apenas produziu filhos ilegítimos, na verdade completamente desintegrados da sociedade de que são fruto, porque não aceites por ela, seja em África, seja em Portugal. Aliás, noutros romances portugueses do mesmo período literário, outros Carlos são vítimas da mesma rejeição e do não reconhecimento familiar e nacional. ${ }^{2}$

Na prosa de A. Lobo Antunes, estas máscaras são portanto usadas como objetos diserts, eloquentes, que "se prendem sempre à intersubjetividade entre autor e leitor" (LEPALUDIER, 2004, p. 97). Este último, acrescenta Lepaludier, “em interação com o texto, investindo-os com a sua atividade cognitiva, percetiva, interpretativa e pulsional, pode neles descobrir a ideologia subjacente" (LEPALUDIER, 2004, p. 59). Neste romance, a problemática é antes de mais nada nacional: a crise simbolizada aqui pela ruptura dos laços familiares é simultaneamente a da sociedade colonial e dum país ironicamente qualificado de "esplendoroso". O próprio título do romance disso dá logo sinal, assim como a citação do hino português em epígrafe remetendo para a dimensão sarcástica de todo o texto. O esplendor de Portugal é uma antiepopeia, como que uma inversão da epopeia cantada pelo hino nacional, que desmonta, com amarga lucidez, o colonialismo português. Nas recordações de Carlos, a vida africana promissora de paz, fartura e felicidade, tão gabada pelo estado português para incentivar os portugueses a emigrarem, é qualificada de "murcha" e de "morna":

[...] fiquei sozinho na cozinha a ouvir o zumbido do frigorífico e a olhar os morros de Almada, a olhar a fazenda do postigo do jipe à medida que nos afastávamos pelos buracos da picada que dividia os girassóis murchos até ao alcatrão, a cantina onde os bailundos compravam cigarros, peixe seco e cerveja morna ao domingo [...], girassóis murchos, arroz murcho, algodão murcho [...] (ANTUNES, 1999, p. 14).

\footnotetext{
2 Por exemplo, em JORGE, Lídia. A costa dos murmúrios. Lisboa: Dom Quixote, 1988. p. 172.
} 
Para reforçar essa ideia, o autor faz um pastiche de um verso do Hino Nacional português: o verso "Nobre povo, Nação valente e imortal" é reinterpretado como "nação sem glória que perdeu todas as ilusões". Este ponto de vista é repetidamente desenvolvido, e a ideologia salazarista desmontada pelo próprio pai de Carlos:

O meu pai costumava explicar que aquilo que tínhamos vindo procurar em África não era dinheiro nem poder mas pretos sem dinheiro e sem poder algum que nos dessem a ilusão do dinheiro e do poder que de facto ainda que o tivéssemos não tínhamos por não sermos mais que tolerados, aceites com desprezo em Portugal, olhados como olhávamos os bailundos que trabalhavam para nós e portanto de certo modo éramos os pretos dos outros da mesma forma que os pretos possuíam os seus pretos e estes os seus pretos ainda em degraus sucessivos descendo ao fundo da miséria, aleijados, leprosos, escravos de escravos, cães, o meu pai costumava explicar que aquilo que tínhamos vindo procurar em África era transformar a vingança de mandar no que fingíamos ser a dignidade de mandar... (ANTUNES, 1999, p. 255).

O autor retoma aqui os termos do discurso do Velho do Restelo de Os Lusíadas, pondo na boca do pai de Carlos um pastiche irônico de versos famosos da epopeia da nação portuguesa cantada por Luís de Camões: “Ó glória de mandar, ó vã cobiça/ Desta vaidade a quem chamamos fama!” (canto IV, estância 95). Desta maneira, a letra do hino português e os versos de Camões podem, por analogia, ser lidos como máscaras, textuais neste caso, por trás das quais se escondem outras realidades, e que denunciam mentiras e hipocrisias dos discursos historiográficos oficiais.

Confrontadas com as máscaras lundas, as personagens de A. Lobo Antunes apresentam comportamentos e reações que evidenciam as marcas indeléveis deixadas na sociedade portuguesa pela colonização, pela guerra colonial e pela descolonização. Elas ilustram perfeitamente o pensamento de E. Lourenço, que comenta assim o grande sentimento de perda e de amputação que sofreram os portugueses com a descolonização:

Treze anos de guerra colonial, queda vertiginosa dum império, tantos eventos que só podem suscitar não só um traumatismo profundo no nosso presente (análogo ao da perda de independência) como um sério questionamento da totalidade da nossa imagem para nós próprios e para o espelho do mundo (LOURENÇO, 1997, p. 107).

\section{Referências}

ANTUNES, António Lobo. O esplendor de Portugal, 3ª ed. Lisboa: Dom Quixote, 1999. BÉDOUIN, Jean-Louis. Les masques. Paris: PUF. Que sais-je?, n. 905, 1961. (Coleção). LEPALUDIER, Laurent. L'Objet et le récit de fiction. Rennes: Presses Universitaires de Rennes, 2004. 
LOURENÇO, Eduardo. Mythologie de la saudade. Paris: Chandeigne, 1997.

MAERTENS, Jean-Thierry. Ritologiques. Tome 3 - Le masque et le miroir: essai d'anthropologie des revêtements faciaux. Paris: Aubier Montaigne, 1978.

REDINHA, José Pedro Domingues. Máscaras e mascarados angolanos. Luanda: Imprensa Nacional de Angola, 1965.

\section{Minicurrículo}

Agnès Levécot é Maître de Conférences Honoraire da Université Sorbonne Nouvelle, membro do CREPAL (Centre de Recherche sur les Pays Lusophones). Integrou várias equipes internacionais de investigação e publicou numerosos artigos em revistas especializadas francesas, portuguesas e brasileiras. Em 2009, a editora L'Harmattan publicou um ensaio sobre o romance português pós-25 de Abril, síntese da sua tese de doutoramento sobre um corpus de 14 autores e 33 obras, intitulado Le roman portugais contemporain. Profondeur du temps. 